\title{
The Research of Software and Technical Personnel Training Mode Based on The Development of Regional Industry
}

\author{
Lai Xiao-ping \\ Department of Information Project, Zhao Qing Science and Technology Polytechnic \\ Zhaoqing Guangdong, China \\ laixiaoping1008@163.com
}

\begin{abstract}
Based on the Pearl River Delta area software industry development present situation analysis, talent demand research and the private higher vocational colleges software technology professional personnel training mode analysis, we found the existing problem of software talent training mode, and reformed with the training experience and college actual situation, to set up the perfect software and technical personnel training mode.
\end{abstract}

Keywords-Higher Vocational Education; Software and Technical; Personnel Training Mode; the Pearl River Delta area

\section{RESEARCH BACKGROUND}

In twenty-first Century, the information age, global information technology brought about a profound change to human production and way of life, and information industry has become the dominant industry to promote economic development. At present, Chinese software industry is still in the growth stage, and its market potential remains untapped. The development of software industry is our country information industry an important planning, in the next five years, software talent demand will show a sharp rise situation. The Ministry of education on talent shortage report points out that software talent structure shows olive type structure, namely the software talents, including the system analyst, project leader, and the lower end of talent, such as software code programmers engaged in basic software development personnel are shortage, and intermediate talents are surplus.

The Pearl River Delta is China's reform and opening up areas, and the most important economic center, it plays a decisive role on the national economic and social development. To accelerate to implement "the Pearl River Delta region reform and development planning outline”, Guangdong Province Education Department has made "Guangdong Province Colleges and universities to implement $<$ the Pearl River Delta region reform and development planning outline> Guidance" (Abbreviation "Guidance"). "Guidance" points out: according to our province industry development and human resources development planning, colleges and universities should adjust specialties, optimize the structure of discipline, and give aid to the professional disciplines adapted to the construction of modern industry system, and actively carry out the discipline reform combined with traditional industrial system, and strengthen the construction of characteristic disciplines, and points out some existing problems of the disciplines construction and the training of talents in higher colleges.

According to "guidance", our college is constantly adjusting and optimizing the structure of discipline and talent training mode. On the basis of more than 10 years good practical experience accumulation of the computer application technology major, we added a new major "Software and Technical" in 2012, that aims to better adapt to the software enterprise's demand for qualified personnel, fill talent gap of the Pearl River Delta region based software technology, and training personnel engaged in software programming.

Local occupation colleges should closely follow the development of regional economy, hold purpose to serve the local economic construction and social development, take the market demand as the guidance, take ability as the standard, strives for the survival by the characteristics, train high-quality software and technical personnel for the Pearl River Delta region needs. We take as the breakthrough point from "national computer technology and software professional and technical qualifications(level) examinations $<$ junior programmer > occupation certification exam outline and content of knowledge, and we found the existing problem of software talent training mode based on the Pearl River Delta area software industry development present situation analysis, software professionals demand investigation and the brothers College of software technology professional personnel training pattern research, combined with the training experience and the practical conditions of our college, we made transformation in training goal, curriculum system, teaching contents and teaching methods and so on, to set up the perfect software and technical personnel training mode. Through this training mode, the talent will be able to go on duty closely, ie graduates are able to quickly adapt to the demands of the job, in the shortest possible time induction, serve for the enterprise, and become an enterprise satisfactory talent, thereby improving the college's reputation, reducing the cost of training, to achieve "win-win ".

\section{THE PEARL River DELTA AREA SOFTWARE INDUSTRY DEVELOPMENT PRESENT SITUATION ANALYSIS}

Pearl River Delta software industry starts earlier, after many years of operation has made considerable development, and it has a certain scale of industry and the independent development ability. Pearl River Delta software industry is mostly concentrated in Shenzhen, Guangzhou, Zhuhai, and 
has formed some software company with a certain scale and market competitiveness, , emerged a batch of star enterprise, such as Huawei, ZTE, Kingdee and KingSoft, they improved the competitiveness of the region.

The Pearl River Delta has a total of four big software park, software park development with their own characteristics: Guangzhou software park mainly develop application software technology products; Zhuhai software park develop general and industry software; software park of Shenzhen focus on the development for Hong Kong and Macao and international market software products; the South Software Park is a type of processing software base. One of the Guangzhou Tianhe Software Park and Zhuhai Southern Software Park is a state-level software industrial base; and the Tianhe Software Park and Shenzhen software park is the base of industry of software of national torch. Shenzhen Software Park is the one of the five national software export base.

Pearl River Delta software industry development is faced with opportunity and challenge. The main problems are:

1 , enterprise dimensions slants small, weakened the ability of software development;

2, high level talent shortage, restricting the software development;

3 , the market environment is non-standard, contused the enthusiasm of the enterprise software development.

However, the implementation of the "Twelfth Five-Year Plan" and policy of software industry brings historical opportunity for the software industry development. Many sectors demand increasingly for application software. Guangdong in the development of information industry software has a strong strength. The "Twelfth Five-Year Plan” points out that the Pearl River Delta can be expand market share, build a strong industrial chain in a number of information industry software market, through developing producer service industry, accelerating the base construction of the national software and information technology services,

\section{PEARL RiVER DelTa SOFTWARE TECHNOLOGY SPECIALIZED TALENT DEMAND RESEARCH}

The higher occupation education training model has been an important question for discussion in the higher vocational colleges. With the actual construction of software technology specialty, we collected many information through visiting the employer, questionnaire survey, data collection and analysis and other means of investigation, such as enterprises demand for talent of computer application, and the enterprise requirements to the software technology professional in knowledge, ability, and quality, the posts ( Group ) fit to the graduates, enterprise values of the occupation qualification certificate and other information. It provides clear direction for our software technology specialty enrollment and employment guidance, and provides basis for the reformation of the professional personnel training mode.

\section{A. The main positions (Group) fit to the graduates}

From the survey, enterprise recruitment main demand or difficult to fill the related position: customer service personnel, administrator, programmer, computer software development engineer, software support/maintenance engineer, software test engineer, webpage design engineer and so on. The graduates are engaged in the main work: software documentation, computer software/hardware sales and maintenance, coding and testing, design and development in WebPages and so on.

\section{B. Occupation quality and ability requirements}

Findings shows, for enterprises when selecting talents, their points of focus are the candidate's ability to analyze and solve problems. That is the key to win in the interview for candidate, Whether understand the industry, whether can actively analyze industry appeared in the latest trends and development situation, whether can understand customer needs, truly for the sake of customers. In addition, master professional knowledge, strong adaptability, be good at learning, with innovative consciousness, can communicate effectively, the team spirit are also the enterprise evaluation standard for graduates. The enterprises hope that the introductions of personnel have both ability and political integrity.

\section{PEARl River Delta’ Private higher Vocational COLLEGES SOFTWARE TECHNOLOGY PROFESSIONAL PERSONNEL TRAINING MODE ANALYSIS}

With the rapid development of software industry and the promotion of teaching mode reformation in higher vocational colleges, higher vocational colleges' software technology specialty is more and more close to software industry, which embodies that the employment promotes the reformation of teaching.

After years of exploration, reform and practice of the higher occupation education, its' running direction is cultivate high-quality, high-skilled talent as the goal. Many higher vocational colleges have implemented a series of reform measures, specifically: the construction of "Double Teachers"; Deepening to the ability-oriented teaching plan reform, renewal and developing school curriculum, to make it more in line with the needs of teaching reform and practice; Specialty setting targeted to the market demand; Pay attention to the construction of students' professional ethics and professional ability training; Innovation oriented by employment, work-study combination mode, the implementation of "order type" talents training mode, and so on.

In the Pearl River Delta Higher Vocational Colleges, software technology specialty talent training mode reform obtained certain result, but there are some problems in the reform and practice as follow.

1) To learn not to use, with low employment rate;

2) Training mode is not completely broken through the education system;

3) The direction of professional development is too broad, the curriculum can not reflect the professional direction;

4) Professional knowledge is updated slowly, insufficient practical training base, training condition is backward. 


\section{IMPLEMENTATION OF SOFTWARE TECHNOLOGY} SPECIALTY TALENTS TRAINING MODE IN OUR COLLEGES

According to the current existing problems of software technology specialty talents training mode in higher vocational education, we made reform to talent training mode, that is "school-enterprise cooperation, work-study combination" talents cultivation mode, which oriented to programmer occupation demand, software industry and enterprises as the basis, occupation ability as the basis.

A. On the basis of the regional development of the software industry needs, determine the personnel training target

Through our research, we timely grasp the needs and change of enterprises, as a starting point to establish and dynamic adjust, constantly revised and updated talents training requirements and specifications of vocational software talents in knowledge, skills and quality. Our cultivation target is to cultivate high-quality skilled talents with sustainable development ability, which have a good occupation morals and spirit of innovation, familiar with computer software and related theoretical knowledge, have a
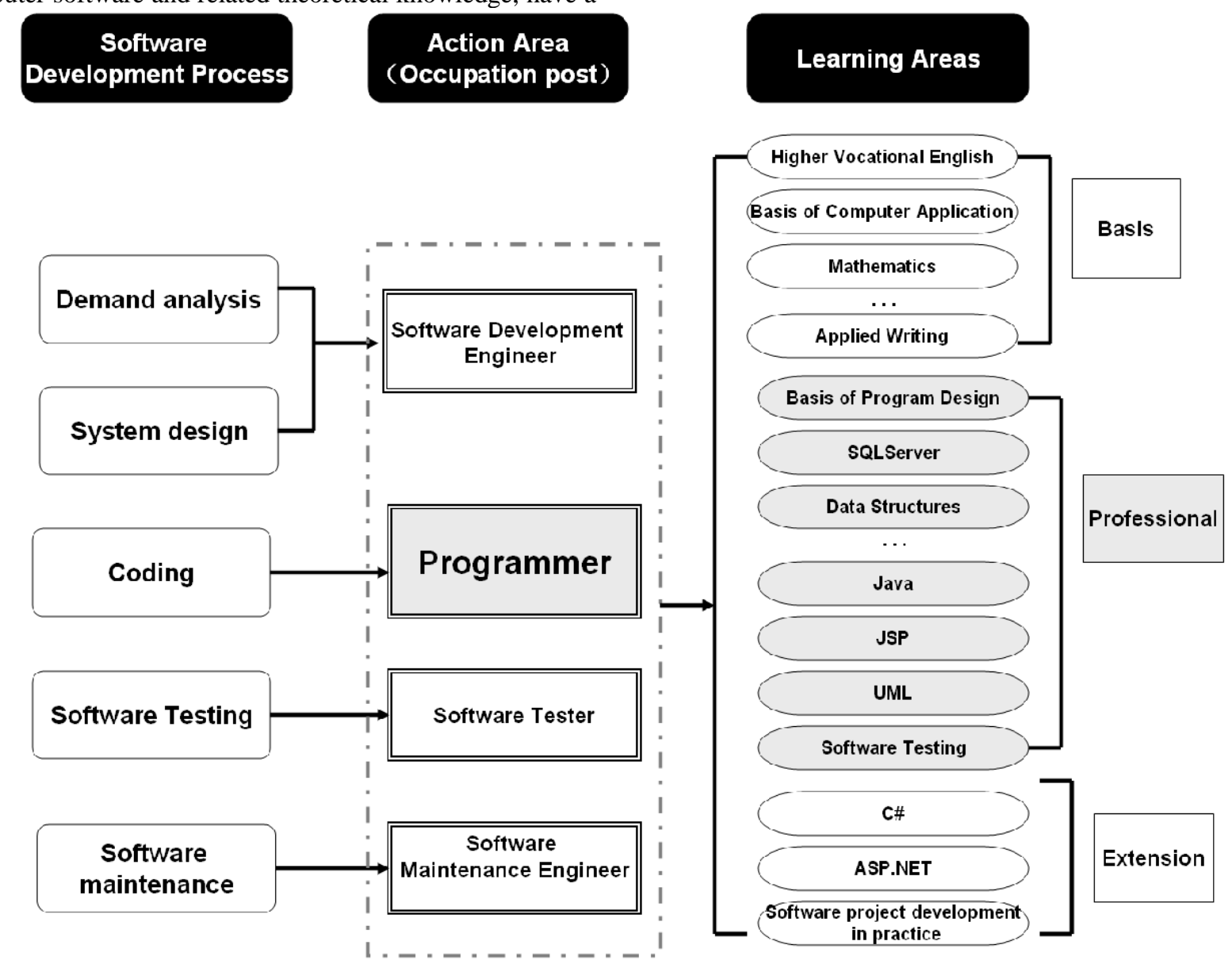

Figure 1. the curriculum system of software technology specialty certain software requirements analysis ability, can complete programming task by programming language, in accordance with the norms of software engineering, can be engaged in the software coding, testing, maintenance and sales of computer software, consulting and technical support work .

According to the business needs, we should timely adjust and refine professional direction, establish the training specifications of talents, develop corresponding teaching plan. Our graduates will be gradually recognized by the enterprises.

In practice, we focus on training program design skill, the core skill of software technology, guide the students to carry out the second classroom, set up a "program design interest group", and establish school-enterprise cooperation with Guangzhou DoDi network science and technology limited company, jointly established "webpage design studio", which enhanced the students' innovation consciousness, improved the practical ability of students. Our students have achieved outstanding results in the national software and webpage design competition, including 2 national awards, and 14 provincial award, the teachers also received excellent guidance titles. 
B. Post demand and occupation standard as the basis, combined with the occupation certification examination, to construct ability oriented curriculum system

Occupation education in professional course is to cultivate the students with the corresponding post (Group) knowledge and skills, improve students' ability to adapt to their future jobs. In the design of curriculum, taking employment as the orientation in the direction of teaching reform, and strive to achieve a combination of three: one is the combination of the teaching requirements with the needs of the market, to establish the "utility, enough, can use" principle of curriculum reform. The two is to adjust the teaching content, professional knowledge and job practice of combining knowledge, the timely introducing of new technology in the software field. Three is the combination of professional ability training with on-the-job training, to strive to make practical training zero distance to experimental training, study zero distance to employment, to improve students' comprehensive qualities, occupation and employment competitiveness. On the basis of the "project for the center, case teaching" teaching ideas, highlight occupation orientation of the professional course, strengthening comprehensive application ability of professional training. We have formed to occupation ability oriented curriculum system through curriculum integration and reconstruction. The Figure 1 shows the curriculum system of software technology specialty.

\section{To Construct curriculum and teaching material system with distinctive characteristics of vocational education}

In establishing a complete curriculum system basis, in order to meet the needs of teaching reform, we should develop school-based teaching materials according to the specific conditions, to enrich morphology (including course standard, teaching material, teaching, courseware, exercises and reference books), and establish curriculum and teaching material system with the obvious characteristics of vocational education. We should break the traditional teaching material compilation mode according to the technical discipline, develop and promote the comprehensive and case course and teaching material closely related to the development of software technology application. We should combine the choice of materials with the practical application of the enterprise, avoiding knowledge of aging; and timely grasp the changes in business needs, and make reasonable adjustment of courses, such as computer software industry's development trend, the advent of new technology, and new tools in the application, to focus on this kind of curriculum.

In the course of reform practice, we continue to accumulate a wealth of teaching resources. We take "Webpage design" curriculum for the pilot, establish the cyber source based on the course of school level excellent courses, and make the course standard of 6 core courses of the software technology professional (database principle and SQL Server, Java, JSP, UML, software testing technology, webpage design). Our the multimedia courseware "webpage design" win the second prize in higher vocational group of the twelfth session of the national competition to get the multimedia courseware, and the corresponding teaching material "webpage design and making" has published by Beijing Normal University press, in addition to our college, Guangdong AIB Polytechnic College, Guangdong Lingnan Institute of Technology and other colleges and universities have selected it. Usage has expanded each year, and the echo is very good.

\section{Strengthening the construction of teacher's troop}

High skilled talents cultivation should be carried out by full-time teachers combined with part-time teachers. Fulltime teachers should learn and train regularly in the corresponding business, and actively cultivate double teacher quality of professional teachers. Special attention should be paid to hire some professional craftsmen with rich practical experience to the school as part-time teachers. In the process of teaching, teachers should adapt to the new teaching mode, convert work role, and strive to become the planner, organization, mobilization and advisory in the learning process.

The professional full-time teachers are the young and middle-aged teachers with rich practical experience and teaching experience. Educational background and professional title structure of our teachers are good, both teaching and research needs. The teacher's troop has distinct characteristics of "double teacher type". They have been ranked in the top ten in the teaching evaluation and annual examination, and publicly published many articles. Their rigorous scholarship and good thinking lay a good foundation for the specialty construction and development.

\section{E. Strengthening students' occupation quality raise}

In our country, occupation education students face enormous employment pressure. Therefore, colleges should carry out systematic and personalized employment guidance and training to help graduates broaden the channels of employment.

We should be fully aware of quality requirements of the occupation school graduates, but not professional skill, to guide students to establish the idea of love this profession, and train students' good personality character and personality charm, such as hard-working, self-motivated, ability to learn, to comply with the rules, obey, communication, attention to quality, honesty, teamwork, responsibility, executive ability, self control, goal consciousness, endurance and so on.

\section{REFERENCES}

[1] The national development and Reform Commission,"Pearl River Delta reform and development planning outline”, Dec,2008.

[2] Guangdong teaches Committee[2009], “Guangdong Province Colleges and universities to implement <the Pearl River Delta region reform and development planning outline > Guidance”,2009.

[3] Zhaoqing Science and Technology Polytechnic information engineering, "software technology professional teaching outline and teaching plan”, 2012.

[4] Sulian Ma, Ying Ma, "Gardening professional personnel training mode”, occupation education research, Vol.7,2008.

[5] Yongqiang Wei, "Software and Technical Personnel Training Mode Based on the CDIO”, Nov,2010.. 
